\title{
Linking Quality and Spending to Measure Value for People with Serious IIIness
}

\author{
Andrew M. Ryan, $\mathrm{PhD}^{1,2}$ and Phillip E. Rodgers, MD, FAAHPM ${ }^{2,3}$
}

\begin{abstract}
Background: Healthcare payment is rapidly evolving to reward value by measuring and paying for quality and spending performance. Rewarding value for the care of seriously ill patients presents unique challenges.

Objective: To evaluate the state of current efforts to measure and reward value for the care of seriously ill patients.

Design: We performed a PubMed search of articles related to (1) measures of spending for people with serious illness and (2) linking spending and quality measures and rewarding performance for the care of people with serious illness. We limited our search to U.S.-based studies published in English between January 1, 1960, and March 31, 2017. We supplemented this search by identifying public programs and other known initiatives that linked quality and spending for the seriously ill and extracted key program elements.

Results: Our search related to linking spending and quality measures and rewarding performance for the care of people with serious illness yielded 277 articles. We identified three current public programs that currently link measures of quality and spending - or are likely to within the next few years - the Oncology Care Model; the Comprehensive End-Stage Renal Disease Model; and Home Health Value-Based Purchasing. Models that link quality and spending consist of four core components: (1) measuring quality, (2) measuring spending, (3) the payment adjustment model, and (4) the linking/incentive model. We found that current efforts to reward value for seriously ill patients are targeted for specific patient populations, do not broadly encourage the use of palliative care, and have not closely aligned quality and spending measures related to palliative care.
\end{abstract}

Conclusions: We develop recommendations for policymakers and stakeholders about how measures of spending and quality can be balanced in value-based payment programs.

Keywords: healthcare payment for serious illness; measuring value of care; rewarding performance; serious illness; spending performance

\section{Introduction}

$\mathbf{V}$ ALUE-BASED PAYMENTS are accelerating rapidly: the Centers for Medicare and Medicaid Services (CMS) seeks to tie $90 \%$ of traditional Medicare payment to measures of quality or value by $2018 .{ }^{1}$ While not the primary target of recent policies, the value of spending on the seriously ill, patients with life-limiting illness, ${ }^{2}$ is receiving increasing atten- tion. High spending during the last year of life is one of the main drivers of spending differences between the United States and peer nations. ${ }^{3}$ Reducing this spending and improving quality of life for seriously ill patients has been recognized as a major opportunity for improvement in U.S. healthcare.

However, linking spending and quality - and rewarding value for patients with serious illness under value-based payment models - presents numerous challenges. First, there

\footnotetext{
${ }^{1}$ Department of Health Management and Policy, University of Michigan School of Public Health, Ann Arbor, Michigan.

${ }^{2}$ Institute for Healthcare Policy and Innovation, University of Michigan, Ann Arbor, Michigan.

${ }^{3}$ Department of Family Medicine, and Division of Geriatric and Palliative Medicine, Department of Internal Medicine, University of Michigan Medical School, Ann Arbor, Michigan.

Accepted September 12, 2017.

This article was developed for, and discussed at, a meeting titled “A Convening on Quality Measures for Serious Illness Care," which was held May 9-11, 2017 in Banff, Canada. The meeting was organized by the Gordon and Betty Moore Foundation, the Cambia Palliative Care Center of Excellence at the University of Washington, the Center to Advance Palliative Care, and the Icahn School of Medicine at Mount Sinai. This supplement is funded by the Gordon and Betty Moore Foundation.
} 
have been limited attempts to develop measures of spending for the seriously ill. Second, quality measures are essential in this context to avoid the appearance of rationing care for the sick and vulnerable at the expense of their well-being and quality of life. Third, where spending and quality measures have been developed, it is unclear how they should be combined. While previous research has catalogued potential approaches to combine quality and spending measures, these methods have not been applied to the seriously ill.

In this article, we review the literature about measuring quality and spending for the seriously ill, linking spending and quality measures, and jointly rewarding spending reductions and quality improvement. We focus our analysis on the literature that can help guide the development of accountability efforts related to care for the seriously ill that combine quality and spending indicators. We close with recommendations for policymakers and stakeholders about how measures of spending and quality can be balanced in value-based payment programs.

\section{Methods}

Our literature review sought to identify literature related to two areas: (1) measures of spending for people with serious illness, and (2) linking spending and quality measures and rewarding performance for the care of people with serious illness. We limited our search to U.S.-based studies published in English between January 1, 1960, and March 31, 2017. We supplemented this search by identifying public programs and other known initiatives that linked quality and spending for the seriously ill. Our search strategy is described in Table 1. We also reviewed articles known to be relevant by the authors, which were not identified in the search.

Models to link quality and spending feature four core components: (1) measuring quality, (2) measuring spending, (3) linking/incentive mechanisms, and (4) payment adjustment mechanisms (Fig. 1). We organized our results according to these components. Measuring quality for the seriously-ill was not the focus of our review. Results from this section are not comprehensive, and instead discuss general principles for measurement.

\section{Results}

\section{Measuring quality for the seriously ill}

Serious illness care may be oriented toward increasing patients' comfort, satisfaction with care, quality-of-life quality, and quality of death, rather than solely on prolonging life. As a result, a patient-centered perspective for quality measurement is essential. ${ }^{5}$ This orientation often requires novel data, including patient registries and surveys of patients and caregivers. ${ }^{6}$ Understanding potentially ineffective treatment, such as the use of chemotherapy within the last 14 days of life, is particularly salient among the seriously ill. Ultimately, quality

Table 1. Description of Literature Search Strategy and Results

\begin{tabular}{|c|c|c|c|}
\hline Search domain & Search query & $\begin{array}{c}\text { Total } \\
\text { articles } \\
\text { identified }\end{array}$ & Relevant articles identified \\
\hline $\begin{array}{l}\text { 1. Measures of spending } \\
\text { for people with serious } \\
\text { illness }\end{array}$ & $\begin{array}{l}\text { ("seriously-ill" [Title/Abstract] OR "Serious illness" } \\
\text { [Title/Abstract] OR "End of life" [Title/Abstract] } \\
\text { OR "Terminal care" [Title/Abstract] OR } \\
\text { "Palliative care" [Title/Abstract] OR "hospice" } \\
\text { [Title/Abstract]) AND ("1960/01/01" [PDAT]: } \\
\text { "2017/03/31"][PDAT]) AND ("Spending" } \\
\text { [Title/Abstract] OR "Cost" [Title/Abstract] OR } \\
\text { "Payment" [Title/Abstract] OR "Efficiency" } \\
\text { [Title/Abstract] OR "Inefficiency" [Title/Abstract]) }\end{array}$ & 2141 & $\begin{array}{l}18 \text { articles that were } \\
\text { relevant for specifying } \\
\text { measures of resource use } \\
\text { or spending for patients } \\
\text { with serious } \\
\text { illness; } \\
15 \text { articles } \\
\text { evaluating the impact of } \\
\text { hospice, palliative care, }\end{array}$ \\
\hline $\begin{array}{l}\text { 2. Linking spending and } \\
\text { quality measures and } \\
\text { rewarding performance } \\
\text { for the care of people } \\
\text { with serious illness }\end{array}$ & $\begin{array}{l}\text { ("seriously-ill" [Title/Abstract] OR "Serious illness" } \\
\text { [Title/Abstract] OR "End of life" [Title/Abstract] } \\
\text { OR "Terminal care" [Title/Abstract] OR "Pallia- } \\
\text { tive care" [Title/Abstract] OR "hospice" [Title/ } \\
\text { Abstract]) AND ("1960/01/01" [PDAT]: "2017/ } \\
\text { 03/31" [PDAT]) AND ("pay for performance" } \\
\text { [Title/Abstract] OR "P4P" [Title/Abstract] OR } \\
\text { "pay for value" [Title/Abstract] OR "financial } \\
\text { incentive" [Title/Abstract] OR "Value-based" } \\
\text { [Title/Abstract] OR "Accountable care" [Title/ } \\
\text { Abstract] OR "ACO" [Title/Abstract] OR } \\
\text { "Bundled payment" [Title/Abstract] OR "bonus" } \\
\text { [Title/Abstract] OR "Reward" [Title/Abstract] OR } \\
\text { "Payment" [Title/Abstract] OR "reimburse*" } \\
\text { [Title/Abstract] OR "incentive*", } \\
\text { [Title/Abstract] OR "Alternative payment" } \\
\text { [Title/Abstract]) }\end{array}$ & 277 & $\begin{array}{l}\text { and advance directives } \\
\text { on spending } \\
\text { (or the cost effectiveness } \\
\text { of these programs); } \\
14 \text { articles related to linking } \\
\text { spending and quality } \\
\text { measures for patients } \\
\text { with serious } \\
\text { illness. }\end{array}$ \\
\hline
\end{tabular}

Search was performed using PubMed database. We combined search terms to identify seriously ill patients and each of the two areas described above. Where possible, our search terms were based on literature search strategies that had been conducted for related topics. After the search was conducted, titles and abstracts of all articles were reviewed for relevance. Of the articles that we deemed to be highly relevant, we reviewed both the citations contained in the article, as well as the articles that cited the article. 


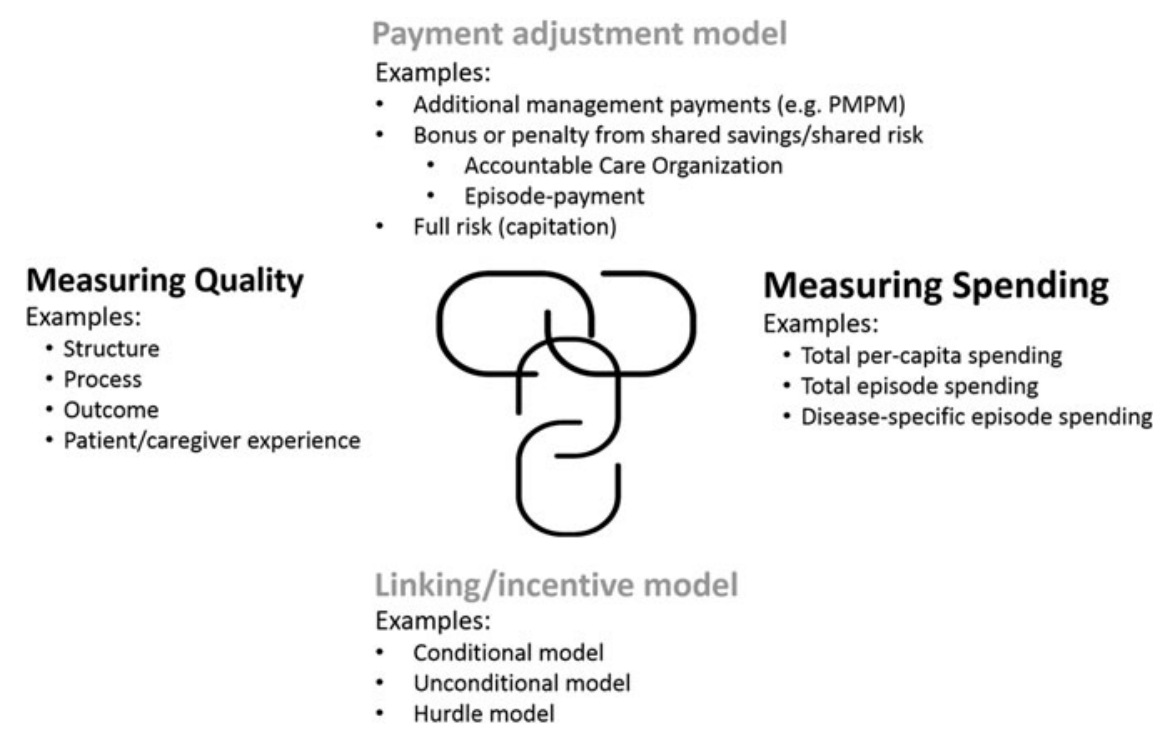

FIG. 1. Components of models to link quality, spending, and payment.

Table 2. Examples of Models to Link Quality, Spending, and Payment for National Programs

\begin{tabular}{|c|c|c|c|c|}
\hline Program & $\begin{array}{l}\text { Payment } \\
\text { adjustment } \\
\text { model }\end{array}$ & $\begin{array}{l}\text { Linking/ } \\
\text { incentive } \\
\text { model }\end{array}$ & Measuring quality & Measuring spending \\
\hline $\begin{array}{l}\text { Comprehensive } \\
\text { ERSD Care } \\
\text { Model }\end{array}$ & $\begin{array}{l}\text { One- or two-sided shared } \\
\text { savings/risk model, } \\
\text { bonus or loss }\end{array}$ & $\begin{array}{l}\text { Spending and } \\
\text { quality } \\
\text { hurdle } \\
\text { + quality } \\
\text { adjustment } \\
\text { model }\end{array}$ & $\begin{array}{l}\text { Clinical measures } \\
(75 \%) \\
-6 \text { process } \\
\text { measures } \\
\text { - } 2 \text { outcome } \\
\text { measures } \\
\text { Reporting measures } \\
(25 \%)\end{array}$ & $\begin{array}{l}\text { Total Medicare Part A and Part B } \\
\text { spending (including dialysis } \\
\text { facilities) }\end{array}$ \\
\hline $\begin{array}{l}\text { Oncology Care } \\
\text { Model }\end{array}$ & $\begin{array}{l} \pm \text { Adjustment to } \\
\text { fee-for-service } \\
\text { payments ( } \$ 160 \text { bonus } \\
\text { for monthly enhanced } \\
\text { oncology } \\
\text { services; performance- } \\
\text { based } \\
\text { payment) }\end{array}$ & $\begin{array}{l}\text { Spending and } \\
\text { quality } \\
\text { hurdle } \\
\text { + quality } \\
\text { adjustment } \\
\text { model }\end{array}$ & $\begin{array}{l}12 \text { measures related to } \\
\text { - Communication } \\
\text { and Care } \\
\text { Coordination } \\
\text { - Person and } \\
\text { Caregiver- } \\
\text { Centered } \\
\text { Experience and } \\
\text { Outcomes } \\
\text { - Clinical Quality of } \\
\text { Care } \\
\text { - Patient Safety }\end{array}$ & $\begin{array}{l}\text { Part A and Part B spending } \\
\text { (and some Part D) for } \\
\text { six-month episodes } \\
\text { (beginning with } \\
\text { chemotherapy initiation) }\end{array}$ \\
\hline $\begin{array}{l}\text { Home Health } \\
\text { Value-Based } \\
\text { Purchasing }\end{array}$ & $\begin{array}{l} \pm \text { Adjustment to Home } \\
\text { Health Prospective } \\
\text { Payment System }\end{array}$ & $\begin{array}{l}\text { Unconditional } \\
\text { model }\end{array}$ & $\begin{array}{l}19 \text { performance } \\
\text { measures }(90 \%) \\
\text { - } 6 \text { process measures } \\
\text { (OASIS) } \\
\text { - } 8 \text { outcome } \\
\text { measures } \\
\text { - } 5 \text { consumer } \\
\text { experience } \\
\text { - (HHCAHPS) } \\
3 \text { reporting measures } \\
\text { (10\%) } \\
\text { - Influenza } \\
\text { - Herpes zoster } \\
\text { - Advanced care } \\
\text { planning }\end{array}$ & None \\
\hline
\end{tabular}


measures should be chosen based on their reliability, validity, clinical relevance, and feasibility to collect. ${ }^{7}$ These measures will also depend on the context of measurement and specific programmatic needs (Table 2).

\section{Measuring spending for people with serious illness}

Articles that evaluated spending and resource use among patients with serious illness used one of two approaches: a retrospective approach, which calculated spending during a specific period of time before death; and a prospective approach, which calculated spending after a specific event. Retrospective approaches to spending evaluated spending patterns of seriously ill patients during a variety of "lookback" periods, including the last $365^{8}$ days and $180,,^{9-12}$ $90,{ }^{13,14} 30,{ }^{15,16} 14,{ }^{17} 7,{ }^{18}$ and $2^{19}$ days of life. Many of these studies also evaluated utilization [e.g., physician visits, ${ }^{13}$ hospitalizations, ${ }^{20}$ emergency department visits, ${ }^{20}$ and intensive care unit (ICU) consultations ${ }^{21}$ ]. Prospective approaches to evaluate spending tend to begin after a specific event. This event was often an initiation of in-home ${ }^{20}$ or hospital-based palliative ${ }^{22}$ care or hospice enrollment. Other studies evaluated spending for terminal episodes in the ICU. Some prospective approaches were not initiated by specific events: one trial of palliative care began evaluating spending for terminally ill patients with an estimated prognosis of a year or less to live. ${ }^{20}$ Under prospective approaches, episodes tend to conclude at the time of a patient's death, rather than a fixed period from the initiation of the episode.

\section{Linking/incentive models}

Four linking/incentive models have been used by sponsors to explicitly link spending and quality indicators to provider reimbursement: unconditional; conditional; quality hurdle; and cost hurdle models.

Unconditional models evaluate quality and spending indicators independently, assign weights to each, and calculate a weighted sum that determines a payment adjustment. This approach has been proposed in Medicare's Hospital ValueBased Purchasing program ${ }^{23}$ and the Hospice Value-Based Payment program. ${ }^{24}$ The downside of unconditional model is that payment incentives can accrue to low-quality providers that also have low spending. ${ }^{25}$

Conditional models evaluate quality and spending indicators jointly, and determine payment incentives based on quality for a given level of spending, or vice versa. This approach currently used the Physician Value-Based Payment Modifier. $^{26}$ The downside of this approach is that it typically requires spending and quality performance to be classified into discrete "cells" of quality and spending performance, leading to threshold effects.

Hurdle models incentivize or penalize providers who meet a minimum performance standard. A quality hurdle model requires a minimum quality standard to be met before savings can be accrued. A spending hurdle model does the same, for spending. Medicare's Shared Savings accountable care organization (ACO) program has elements of both quality and spending hurdles: savings can accrue only to ACOs that surpass the minimum savings rate and meet a minimum quality standard. Above the hurdle, ACOs' rate of shared savings then depends on the level of quality performance. Under two-sided risk models, financial losses become less severe for ACOs with higher quality performance.

\section{Examples of programs and payment adjustment models linking quality and spending for the seriously ill}

A number of articles discussed conceptual issues associated with the move toward alternative payment models for patients with serious illness. These articles tended to focus on palliative care related to oncology. ${ }^{27-29}$ Others emphasized the move toward alternative payment models among commercial insurers. ${ }^{30}$ Research anticipating the potential impact of payment reform found that reductions in chemotherapy reimbursement from the Medicare Modernization Act led to less intensive oncology care at the end of life. ${ }^{31}$ Another study found that the Physician Group Practice Demonstration, a precursor to ACO programs, was not associated with changes in cancer spending. ${ }^{32}$ A recent study of oncology care models sponsored by the Center for Medicare and Medicaid Innovation (CMMI) found that the oncology medical home and patient navigation models led to reduced spending in the last 30, 90, and 180 days of life. ${ }^{14} \mathrm{CMMI}$ has also funded Four Seasons Hospice and Palliative Care to expand palliative care delivery outside the hospital and offset hospital spending by providing more effective communitybased patient and caregiver support services. ${ }^{33}$

Additional work has showed that palliative care embedded within an ACO was associated with greater savings. ${ }^{34}$ The Trinity Pioneer ACO of Iowa focused on palliative care services as a way to generate savings, mainly by increasing the number of palliative care consultations. Some evidence suggests that delivery systems have reduced treatment costs through the use of palliative care, which is relevant for ACO models. ${ }^{35}$ This has been accomplished by the Palliative Care Benchmarking Project by defining "high-risk" patients for palliative care based on admission for one of 26 Diagnosis Related Groups (DRGs) ${ }^{36}$ and using rates of palliative care consultations among eligible patients as a quality measure. The use of ACOs to advance palliative care is similar to managed care efforts to coordinate palliative care around a capitated payment model that was developed almost two decades ago. ${ }^{37,38}$

Table 2 shows how three national programs for seriously ill patients have linked measures of quality and spending to adjust payment to providers. The Comprehensive End-Stage Renal Disease (ERSD) Care Model is an ACO program. While its approach to assigning beneficiaries and evaluating spending and quality is similar to the other CMS ACO models, the ERSD model is unique in its exclusive focus on a seriously ill population. The program uses a hurdle model to adjust the shared savings or losses incurred by ACOs based on their quality performance. The program has been implemented recently but not yet evaluated.

CMS has also developed the Oncology Care Model, an episode-based payment model. Under this model, hospitals are at risk for all hospital and physician spending, and some prescription drug spending, in the six months following the start of chemotherapy. Participating providers receive a maintenance fee for each patient treated under the model and are eligible for shared savings or shared losses based on their quality and spending performance (determined by the hurdle 
model). This payment model, however, is not focused exclusively on seriously ill patients with life-limiting illness, and also includes patients who may be cured by therapy.

Home Health Value-Based Purchasing is another payment model that focuses, in part, on the seriously ill population. This program, modeled on the Hospital Value-Based Purchasing, adjusts payment for hospice providers based on a series of quality and spending measures. Payment adjustments are will be made to the Home Health Prospective Payment System using the unconditional model. Payment adjustments are expected begin at $\pm 3 \%$ of hospice payment in 2018 , increasing to $8 \%$ by 2022 .

\section{Discussion}

\section{Within or apart: Creating separate models of incorporating seriously ill patients within extant models}

Any programs that financially reward quality and spending performance for serious illness care would be implemented alongside alternative payment models that have already been implemented. Should initiatives for serious illness care be incorporated into extant programs, or should they become their own programs? The benefits of incorporating the seriously ill into extant programs are that they can draw on the structures and processes that have been developed to manage population health. The drawbacks are that these structures, particularly their quality and spending measures, may not be appropriate for serious illness care. For instance, hospice providers are rarely included in ACOs. ${ }^{39}$

The advantage of separate accountability programs for serious illness care is to enable a greater focus on the needs of the patients and caregivers receiving it. Such programs could conceivably have more clinical homogeneity and clearer expectations about spending and quality across the disease course. This could help align the specifications of spending and quality measures. However, even within common disease areas such as cancer, there can be extensive clinical heterogeneity for different types of disease (e.g., breast cancer, prostate cancer, esophageal cancer, and lung cancer). The disadvantages of separate programs for the seriously ill are that numerous programs could create administrative complexity for providers and payers, and confusion for patients and caregivers. Given the rise of multimorbidity in the United States, different patients could conceivably be eligible for numerous programs, ${ }^{40}$ creating potential problems related to coordination and accountability across programs. In addition, the number of patients qualifying for these separate programs would likely be small, leading to unreliability in performance measures for spending and quality. One option could involve combining multiple payers in an initiative, as had been done in the Oncology Care Model.

\section{Defining eligible patients and accountable clinicians}

Eligibility among seriously ill patients for eccountability programs may be based on some or all of the following patient characteristics: serious illness diagnosis (e.g., advanced cancer, heart failure, and neurodegenerative illness); functional and nutritional decline; patterns of healthcare utilization; or receipt of certain types of care (e.g., hospice care and palliative care). Patient consent is essential, and while ob- taining consent would introduce programmatic complexity, it would mitigate concerns that serious illness care may be saving money at patients' expense.

Given the diverse care needs of seriously ill patients, having individual hospitals or physician practices be accountable for care creates significant challenges with respect to both proactively identifying patients who can benefit from palliative care services and influencing the continuum of care. Larger care systems, such as integrated delivery systems, Medicare Advantage plans, or ACOs may be better structured to be accountable for the care of seriously ill patients $^{33,27}$ However, larger organizations may not have the clinical delivery capacity to meet the palliative care needs of their populations, especially in rural communities or highly competitive markets. Bridging these gaps requires flexible payment models that are oriented toward care coordination and clinical consultation ${ }^{41}$ among diverse practices, rather than a one-size-fit all approach.

\section{Defining the period of accountability}

After patients meet clinical criteria for a given care model, a prospective episode can then be initiated. There is some precedence for this approach for the seriously ill: a prognosis of one year or less left could be an inclusion criterion for an alternative payment model. The end of the episode could be the death of the patient the desire of the patient to end the episode, or the patient's loss of eligibility. This is the approach taken in Medicare's ERSD Comprehensive Care Model. The Oncology Care Model initiates at the beginning of chemotherapy and extends for six months. Initiation of hospice or palliative care is another trigger to begin an episode. The drawback with this approach is that it is potentially at odds with the larger goals of palliative care, which are not so much to reduce spending after the start of hospice care or palliative care, but to encourage more hospice and palliative care. A retrospective episode, on the other hand, evaluates quality and spending in over a specified period preceding death. Because interventions focused on the seriously ill have the potential to affect both patients' time to death and spending at the end of life, the use of prospective and retrospective episodes may result in different inferences about the impact of an intervention. ${ }^{42}$ As a result, the choice of a prospective or retrospective episode should be guided by the goals and expectations of the program or intervention.

\section{Determining the types of care for which clinicians are accountable}

Payers have different options for determining the types of care that would be included in episodes of serious illness. Episodes could be defined broadly, and accountable providers would thus be responsible for all healthcare used by patients, even that which is not necessarily related to the serious illness. Alternatively, an episode could be defined narrowly and accountable providers held responsible only for care related to the given serious illness. Broad episodes make sense for hospice and palliative care when a key goal is to avoid aggressive treatment ${ }^{43}$ that does not improve either disease progression or quality of life. Narrow bundles may be more appropriate for hospice and palliative care providers caring for patients who are continuing to receive potentially valuable disease-oriented care like chemotherapy. Research 
suggests that episode spending tends to be highly consistent, regardless of broad or narrow definitions. ${ }^{44}$

\section{Setting targets for spending}

Alternative payment models are evolving toward partial risk approaches that include upside and downside risk with quality adjustment. ${ }^{45}$ This involves setting a target for spending and comparing the spending of the accountable provider with the target. Under a one-sided "shared savings" model, if spending if below the target, the accountable provider shares some of the savings that are generated. Under a two-sided model, an accountable provider risks losing revenue for spending above the target. Medicare is moving away from one-sided models toward two-sided risk: under the MACRA legislation, two-sided risk is required for providers to meet the criteria for "advanced" alternative payment models.

Spending on medical care is likely to vary considerably in an episode of serious illness, with spending increasing toward the end of life. ${ }^{9,46-48}$ Spending targets should account for these trajectories, adjusting for time periods when patients are closer to the end of life. Practically speaking, this means that spending expectations should be higher for a patient with an episode of serious illness that last four months, compared to an episode lasting 24 months.

Finally, setting spending targets for patients with very high spending will be a challenge. Medicare's bundled payment and ACO programs have explicit rules to limit providers' risk for high spending patients, capping the spending for which accountable providers are responsible at the 95th percentile or two standard deviations from the mean. Payers could take a similar approach for episode payments among the seriously ill. Yet because so much of health spending is concentrated among the highest cost patients, many of whom have serious illness, excluding these patients from accountability programs misses an important opportunity for savings. Efforts to prospectively identify patients at risk for very high spending, segmenting this population, and providing upside risk alone for the spending, may be one approach to balance incentives for efficiency, while avoiding excess risk for providers.

\section{Avoiding unintended consequences of rewarding quality and spending for seriously ill}

Due to the vulnerability of seriously ill patients, programs that link quality and spending must anticipate and safeguard against unintended consequences. One potential unintended consequence is that providers would seek to avoid caring for seriously ill patients who appear to be particularly costly. Published data show that some hospices restrict enrollment for high cost patients, ${ }^{49}$ while others limit admission for patients with shorter, and less profitable, expected lengths of stay. ${ }^{50}$ Relatedly, because many costs associated seriousillness care accrue close to death, providers have an incentive to decline patients with very short life expectancies. These concerns could be remediated through robust risk adjustment, use of alternative risk models for particularly costly patients, and monitoring the life expectancy of patients who are enrolled in palliative care programs. Another unintended consequence is that providers could attempt to reduce spending at the expense of quality. Ensuring robust quality standards, potential extensive performance measures, and the use of quality hurdle payment models, could alleviate this concern.

\section{Conclusion}

In this article, we identified and evaluated key programs and program features for accountability efforts related to care for the seriously ill that combine quality and spending indicators. Future research should evaluate the measurement properties for quality and spending indicators focused on the seriously ill, hopefully culminating in new measures that are endorsed by the National Quality Forum. In addition, research should evaluate the impact of programs focused on improving value for seriously-ill populations, such as the ERSD ACO program, the Oncology Care Model, and the Home Health Value-Based Payment program.

\section{Author Disclosure Statement}

This article was commissioned by the Moore Foundation. Funding for Andrew Ryan comes from the Moore Foundation.

\section{References}

1. Burwell SM: Setting value-based payment goals-HHS efforts to improve U.S. health care. N Engl J Med 2015;372:897-899.

2. Kelley AS: Defining "serious illness." J Palliat Med 2014; 17:985.

3. Bekelman JE, Halpern SD, Blankart CR, et al.: Comparison of site of death, health care utilization, and hospital expenditures for patients dying with cancer in 7 developed countries. JAMA 2016;315:272-283.

4. Ryan AM, Tompkins CP, Markovitz AA, Burstin HR: Linking spending and quality indicators to measure value and efficiency in health care. Med Care Res Rev 2017;74:452-485.

5. Montgomery K, Little M: Enriching patient-centered care in serious illness: A focus on patients' experiences of agency. Milbank Q 2011;89:381-398.

6. Teno JM, Price RA, Makaroun LK: Challenges of measuring quality of community-based programs for seriously ill individuals and their families. Heal Aff 2017;36:1227-1233.

7. Hyder JA, Roy N, Wakeam E, et al.: Performance measurement in surgery through the National Quality Forum. J Am Coll Surg 2014;219:1037-1046.

8. Campbell DE, Lynn J, Louis TA, Shugarman LR: Medicare program expenditures associated with hospice use. Ann Intern Med 2004;140:269-277.

9. Bramley T, Antao V, Lunacsek O, et al.: The economic burden of end-of-life care in metastatic breast cancer. J Med Econ 2016;19:1075-1080.

10. Nicholas LH, Langa KM, Iwashyna TJ, Weir DR: Regional variation in the association between advance directives and endof-life Medicare expenditures. JAMA 2011;306:1447-1453.

11. Zuckerman RB, Stearns SC, Sheingold SH: Hospice use, hospitalization, and Medicare spending at the end of life. J Gerontol B 2016;71:569-580.

12. Byhoff E, Harris JA, Langa KM, Iwashyna TJ: Racial and ethnic differences in end-of-life Medicare expenditures. J Am Geriatr Soc 2016;64:1789-1797.

13. Barnato AE, Farrell MH, Chang C-CH, et al.: Development and validation of hospital "end-of-life" treatment intensity measures. Med Care 2009;47:1098-1105.

14. Colligan EM, Ewald E, Ruiz S, et al.: Innovative oncology care models improve end-of-life quality, reduce utilization and spending. Health Aff (Millwood) 2017;36:433-440.

15. Gozalo P, Plotzke M, Mor V, et al.: Changes in Medicare costs with the growth of hospice care in nursing homes. $\mathrm{N}$ Engl J Med 2015;372:1823-1831. 
16. Brian Cassel J, Kerr KM, McClish DK, et al.: Effect of a home-based palliative care program on healthcare use and costs. J Am Geriatr Soc 2016;64:2288-2295.

17. Kelley AS, Deb P, Du Q, et al.: Hospice enrollment saves money for Medicare and improves care quality across a number of different lengths-of-stay. Health Aff (Millwood) 2013;32:552-561.

18. Zhang B, Wright AA, Huskamp HA, et al.: Health care costs in the last week of life: Associations with end-of-life conversations. Arch Intern Med 2009;169:480-488.

19. Unroe KT, Sachs GA, Dennis ME, et al.: Effect of hospice use on costs of care for long-stay nursing home decedents. J Am Geriatr Soc 2016;64:723-730.

20. Brumley R, Enguidanos S, Jamison P, et al.: Increased satisfaction with care and lower costs: Results of a randomized trial of in-home palliative care. J Am Geriatr Soc 2007;55:993-1000.

21. Lukas L, Foltz C, Paxton H: Hospital outcomes for a homebased palliative medicine consulting service. J Palliat Med 2013;16:179-184.

22. Morrison RS, Penrod JD, Cassel JB, et al.: Cost savings associated with US hospital palliative care consultation programs. Arch Intern Med 2008;168:1783-1790.

23. Ryan AM, Burgess JFJ, Pesko MF, et al.: The early effects of Medicare's mandatory hospital pay-for-performance program. Health Serv Res 2015;50:81-97.

24. Nowak BP: Hospice value-based purchasing program: A model design. J Pain Symptom Manage 2016;52:892-900.

25. Das A, Norton EC, Miller DC, et al.: Adding a spending metric to Medicare's value-based purchasing program rewarded low-quality hospitals. Health Aff (Millwood) 2016; 35:898-906.

26. Ryan AM, Press MJ: Value-based payment for physicians in Medicare: Small step or giant leap? Ann Intern Med 2014; 160:565-566.

27. Smith G, Bernacki R, Block SD: The role of palliative care in population management and accountable care organizations. J Palliat Med 2015;18:486-494.

28. Shulman LN: The effect of accountable care organizations on oncology practice. Am Soc Clin Oncol Educ Book 2014; e468-e471.

29. Cox J V, Ward JC, Hornberger JC, et al.: Community oncology in an era of payment reform. Am Soc Clin Oncol Educ Book 2014:e447-e452.

30. Greenapple R: Rapid expansion of new oncology care delivery payment models: Results from a payer survey. Am Health Drug Benefits 2013;6:249-256.

31. Colla CH, Morden NE, Skinner JS, et al.: Impact of payment reform on chemotherapy at the end of life. J Oncol Pract 2012;8(3 Suppl):e6s-e13s.

32. Colla CH, Lewis VA, Gottlieb DJ, Fisher ES: Cancer spending and accountable care organizations: Evidence from the Physician Group Practice Demonstration. Healthc (Amsterdam, Netherlands) 2013;1:100-107.

33. Taylor D, Harker M, Olson A, Bull J: How can we increase the use of palliative care in Medicare? Health Affairs Blog. http://healthaffairs.org/blog/2017/02/13/how-can-we-increasethe-use-of-palliative-care-in-medicare (last accessed October 3, 2017).

34. Lustbader D, Mudra M, Romano C, et al.: The impact of a home-based palliative care program in an accountable care organization. J Palliat Med 2017;20:23-28.

35. Isenberg SR, Lu C, McQuade J, et al.: Impact of a new palliative care program on health system finances: An anal- ysis of the palliative care program inpatient unit and consultations at Johns Hopkins Medical Institutions. J Oncol Pract 2017;13:e421-e430.

36. Bernacki RE, Ko DN, Higgins $P$, et al.: Improving access to palliative care through an innovative quality improvement initiative: An opportunity for pay-for-performance. J Palliat Med 2012;15:192-199.

37. Mahoney JJ: Hospice and managed care. Hosp J 1997;12: 81-84.

38. Lynn J, Wilkinson A, Cohn F, Jones SB: Capitated riskbearing managed care systems could improve end-of-life care. J Am Geriatr Soc 1998;46:322-330.

39. Colla CH, Lewis VA, Shortell SM, Fisher ES: First national survey of ACOs finds that physicians are playing strong leadership and ownership roles. Health Aff (Millwood) 2014; 33:964-971.

40. Pefoyo AJK, Bronskill SE, Gruneir A, et al.: The increasing burden and complexity of multimorbidity. BMC Public Health 2015;15:415.

41. Teno JM, Plotzke M, Christian T, Gozalo P: Examining variation in hospice visits by professional staff in the last 2 days of life. JAMA Intern Med 2016;176:364-370.

42. May P, Normand C: Analyzing the impact of palliative care interventions on cost of hospitalization: Practical guidance for choice of dependent variable. J Pain Symptom Manage 2016;52:100-106.

43. Brooks GA, Li L, Uno H, et al.: Acute hospital care is the chief driver of regional spending variation in Medicare patients with advanced cancer. Health Aff (Millwood) 2014; 33:1793-1800.

44. Ellimoottil C, Ryan AM, Hou H, et al.: Implications of the definition of an episode of care used in the comprehensive care for joint replacement model. JAMA Surg 2017;152:49-54.

45. Rosenthal MB, Cutler DM, Feder J: The ACO rulesstriking the balance between participation and transformative potential. N Engl J Med 2011;365:e6.

46. Hogan C, Lunney J, Gabel J, Lynn J: Medicare beneficiaries' costs of care in the last year of life. Health Aff (Millwood) 2001;20:188-195.

47. Obi EN, Swindle JP, Turner SJ, et al.: Health care costs for patients with heart failure escalate nearly 3-fold in final months of life. J Manag care Spec Pharm 2016;22:1446-1456.

48. von Wyl V, Telser H, Weber A, et al.: Cost trajectories from the final life year reveal intensity of end-of-life care and can help to guide palliative care interventions. BMJ Support Palliat Care 2015 [Epub ahead of print]; doi:10.1136/ bmjspcare-2014-000784.

49. Aldridge Carlson MD, Barry CL, Cherlin EJ, et al.: Hospices' enrollment policies may contribute to underuse of hospice care in the United States. Health Aff (Millwood) 2012;31:2690-2698.

50. Lindrooth RC, Weisbrod BA: Do religious nonprofit and forprofit organizations respond differently to financial incentives? The hospice industry. J Health Econ 2007;26:342-357.

Address correspondence to: Andrew M. Ryan, PhD Department of Health Management and Policy University of Michigan School of Public Health 1415 Washington Heights, SPH II, Room M3124 Ann Arbor, MI 48109

E-mail: amryan@umich.edu 